Vol 5 No 1 (2022) 60-70 P-ISSN 2620-295 E-ISSN 2747-0490

DOI: 1047467/elmal.v5i1.633

\title{
Pengaruh Promosi, Kualitas Pelayanan, dan Implementasi Syariah terhadap Minat Masyarakat Menggunakan Jasa Pegadaian Syariah
}

\author{
Nia Ruhaniah', Hendri Tanjung1, Hilman Hakiem³ \\ 1,2,3 Universitas Ibn Khaldun Bogor \\ haniahruhaniah@gmail.com ${ }^{1}$
}

\begin{abstract}
ABSRACK
This study aims to determine how much influence the promotion, service quality, and implementation of sharia has on people's interest in using sharia pawnshops. This study uses quantitative methods by distributingquestionnaires online or google forms to respondents with criteria aged 20-40 years and knowing about sharia pawnshops. This research was conducted in the city of Depok with a total of 100 respondents. In this study, it was found that the promotion and service quality variables had a significant effect, while the sharia implementation variable had no significant effect. In addition, in this study it was also found that the $Y$ variable could be explained by $71.3 \%$ by the $X$ variable. and the remaining $28.7 \%$ was explained by other variables outside the study.
\end{abstract}

Keyword: Promotion, Service Quality, Syariah Implementation, and Interest

\section{ABSTRAK}

Penelitian ini bertujuan untuk mengetahui seberapa besar penngaruh dari promoosi, kualitas pelayanan, dan implementasi syariah terhadap minat masyarakat menggunakan jasa pegadaian syariah. Penelitian ini menggunakan metode kuantitatif dengan cara menyebarkan kuesioner online atau google form kepada responden dengan kriteria berusia 20-40 tahun dan mengetahui tentang pegadaian syariah. Penelitian ini dilakukan di Kota Depok dengan Jumlah responden sebanyak 100 responden. Dalam penelitian ini ditemukan bahwa variabel promosi dan kualitas pelayanan berpengaruh signifikan, sedangkan variabel implementasi syariah tidak berpengaruh secara signifikan. Selain itu dalam penelitian ini juga ditemukan bahwa variabel Y dapat dijelaskan sebesar 71,3\% oleh variabel X. dan sisanya sebesar $28,7 \%$ dijelaskan oleh variabel lain diluar penelitian.

Kata Kunci : Promosi, Kualitas Pelayanan, Implementasi Syariah, dan Minat 


\section{Vol 5 No 1 (2022) 60-70 P-ISSN 2620-295 E-ISSN 2747-0490 DOI: $1047467 /$ elmal.v5i1.633}

\section{PENDAHULUAN}

Pegadaian syariah merupakan sebuah lembaga yang memberikan jasa pembiayaan terhadap masyarakat dengan menggunakan barang berharga sebagai jaminan dari hutang yang diberikan. Menurut fatwa MUI pegadaian syariah adalah lembaga keuangan dengan menganut sistem gadai berlandaskan pada prinsip-prinsip keislaman.

Awal mulanya gadai di indonesia adalah dengan di dirikannya Bank Van Leening yang didirikan di Batavia oleh Belanda, lebih tepatnya pada 20 Agustus 1764. Namun setelah Inggris mengambil alih Indonesia dari Belanda, Bank Van Leening dibubarkan, dan setiap masyarakkat diperbolehkan membuat pegadaian dengan izin pemerintah setempat. Namun kebijakan ini tidak memberikan hasil yang positif untuk masyarakat karna menerapkan sistem bunga didalamnya. Kemudian pada 1 April 1901 Didirikan pegadaian pertama di Sukabumi. Ini adalah awal mula pegadaian di Indonesia. Sampai saat ini pegadaian sudah mengalami beberapa kali perubahan status, diantaranya: sejak 1 Januari 1961 pegadaian ditetapkan sebagai Perusahaan Negara (PN), kemudian berubah menjadi Perusahaan Jawatan berdasarkan Peraturan Pemerintah (PP) Nomor 7 Tahun 1961, dan berdasarkan Peraturan Pemerintah Nomor 10 Tahun 1990. Status pegadaian kembali berubah menjadi Perusahaan Umum (PERUM) hingga sekarang.

Pegadaian syariah pertama di Indonesia didirikan di jakarta pada Januari 2003 dengan nama Unit Layanan Gadai Syariah. Sejak Januari 2003 sampai September 2003 telah didirikan beberapa pegadaian syariah lainnya di Surabaya, Semarang, Makassar, Surakarta, Yogyakarta, dan 4 pegadaian di Aceh dikonversi menjadi pegadaian syariah. Pegadaian Syariah dalam menjalankan operasionalnya berpegang kepada prinsip syariah. Produk syariah pada dasarnya tidak menggunakan bunga karena riba, dan menetapkan uang sebagai alat tukar bukan sebagai komoditas yang diperdagangkan, juga melakukan bisnis untuk memperoleh imbalan atas jasa atau bagi hasil. Sampai pada tahun 2019 pegadaian telah memiliki 4.500 outlet dimana lebih dari 700 outlet-nya adalah pegadaian syariah.

Dasar hukum didirikannya pegadaian syariah dapat dilihat dalam PP No.51 Tahun 2011 tentang Perubahan Bentuk Badan Hukum Perum Pegadaian Menjadi Perusahaan Perseroan Pegadaian (Persero). Peraturan ini secara langsung mengatur dan memberi peluang bagi pengembangan Pegadaian Syariah di PT Pegadaian (Persero). Selain peraturan diatas ada beberapa landasan hukum yang dapat dijadikan rujukan dalam melakukan transaksi gadai adalah :

(1) Fatwa Dewan Syariah Nasional No.25/DSN-MUI/III/2002 tentang Rahn;

(2) Fatwa Dewan Syariah Nasional No.26/DSN-MUI/III/2002 tentang Rahn Emas; 


\section{Vol 5 No 1 (2022) 60-70 P-ISSN 2620-295 E-ISSN 2747-0490 DOI: 1047467/elmal.v5i1.633}

(3) Fatwa Dewan Syariah Nasional No.68/DSN-MUI/III/2008 tentang RahnTasjily; dan

(4) Fatwa Dewan Syariah Nasional No.92/DSN-MUI/IV/2014 tentang Pembiayaan yang disertai Rahn (al-tamwil al-mautsuq bi al-rahn).

Selain itu, terdapat sebelas peraturan perundang-undangan lain yang secara tidak langsung mengatur, dan memberi peluang bagi pengembangan Pegadaian Syariah di Indonesia, yaitu: (1) UUD1945; (2) KUHP perdata; (3) UU Lelang (Vendu Reglement Ordonantie); (4) UU No.25 Tahun 1992 tentang Koperasi; (5) UU No.8 Tahun 1999 tentang Perlindungan Konsumen; (6) UU No.42 Tahun 1999 tentang Jaminan Fidusia; (7) UU No.5 Tahun 1999 tentang Larangan Praktek Monopoli dan Persaingan Usaha Tidak Sehat; (8) UU No.19 Tahun 2003 tentang BUMN; (9) UU No.40 Tahun 2007 tentang Perseroan Terbatas; (10) UU No.20 Tahun 2008 tentang UMKM; dan (11) UU No.8 Tahun 2010 tentang Pencegahan dan Pemberantasan Tindak Pidana Pencucian Uang. (Mulazid : 2012).

\section{TINJAUAN LITERATUR}

\section{Promosi}

Menurut Kamus Besar Bahasa Indonesia promosi adalah kegiatan komunikasi untuk meningkatkan penjualan dengan pameran, periklanan, demonstrasi, dan usaha yang lain yang bersifat persuasif.

Menurut (Philip Kotler:1997) mendefinisikan promosi adalah suatu kegiatan yang dilakukan oleh perusahaan untuk mengkomunikasikan manfaat dari produknya dan untuk meyakinkan konsumen agar membeli.

Menurut (Julian Cummins:1991) mendefinisikan promosi sebagai serangkaian teknik yang digunakan untuk mencapai sasaran penjualan atau pemasaran dengan penggunan biaya yang efektif, dengan memberikan nilai tambah pada produk atau jasa baik kepada para perantara maupun pemakai langsung, yang tidak dibatasi dalam jangka waktu tertentu.

Menurut Philip Kotler dalam Warnadi dan Aris (2019:93) ada beberapa strategi promosi yang menggunakan public relationship, dan disingkat menjadi P-EN-C-I-L-S.

a. Publication (publikasi). Perusahaan dapat mengusahakan penerbitanpenerbitan tertentu unuk menningkatkan citra perusahaan.

b. Event (kegiatan). Kegiatan yang dirancang secara tepat dapat mencapai tujuan public relation tertentu.

c. News (pemberitaan). Perusahaan bisa membuat sesuatu atau melakukan kegiatan agar menjadi pemberitaan dan masyarakat semakin mengenal perusahaan. 


\section{Vol 5 No 1 (2022) 60-70 P-ISSN 2620-295 E-ISSN 2747-0490 DOI: $1047467 /$ elmal.v5i1.633}

d. Community invol vement (kepedulian kepada masyarakat). Agar perusahaan memiliki citra dan kesan yang baik dimata masyarakat, perusahaan harus menunjukan kepeduliannya terhadap masyarakat, teruama saat cabang baru dibuka disuatu daerah.

e. Identity media. Menggunakan media sebagai identitas, yaitu menamai semua stationery seperti kartu nama, kertas, amplop, bahkan sarana dan rasarana seperti gedung, mobil, dll.

f. Lobbying (mempengaruhi). Perusahaan dapat melakukan kontak pribadi secara informal untuk mencapai tujuan-tujuan tertentu.

g. Social investment. Perusahaan dapat mencuri hati dan membuat kesan baik kepada masyarakat atau pasar yang ditujunya dengan cara melakukan partisipasi sosial seperti membangun jalan, masjid, dll.

Menurut Freedy Rangkuti (2013:177) Kegiatan promosi juga berfungsi sebagai alat komunikasi antara perusahaan dan konsumen dalam kegiatan pembelian sesuai keinginan dan kebutuhannya.

\section{Kualitas Pelayanan}

Menururt Tjiptono dalam Mu'ah dan Masram (2021:54) mengatakan bahwa kualitas adalah ukuran kebaikan suatu produk atau jasa yang terdiri dari kualitas desain dan kualitas kesesuaian.

Menurut Armand Vallin Feigenbaum dalam Farizal Amin (2019) kualitas adalah gabungan karakteristik produk dan jasa yang meliputi kegiatan pemasaran, rekayasa teknik, produksi, dan perawatan yang membuat produk dan jasa tersebut dapat memenuhi keinginan pelanggan.

Menrut Kotler dalam Mu'ah dan Masram (2021:54) mengatakan bahwa pelayanan adalah setiap tindakan atau perbuatan yang dapat ditawarkan satu pihak kepada pihak lain, yang pada dasarnya tidak berwujud dan tidak mengakibatkan kepemilikan apapun.

Menurut Tjiptono dalam Feti Rukmanasari (2017:31) mengatakan bahwa pelayanan adalah tingkat mutu dari suatu yang ditawarkan dari satu pihak kepihak lain, yaitu dari perusahaan kepada konsumen. Kualitas pelayanan ada karna kebutuhan pelanggan dan berakhir dengan penilaian pelanggan, dengan ini berarti kualitas yang baik bukanlah ditentukan oleh perusahaan melainkan ditentukan dengan persepsi pelanggan.

Menurut Valarie dalam Antonius dan Antonina (2006:344) menyatakan bahwa ada 10 dimensi penilaian atas kualitas pelayanan yaitu: Tampilan (tangibles), keandalan (reliability), tanggap (responsiviness), kompetisi (competence), kesopanan (courtesy), kepercayaan (credibility), keamanan (security), keterbukaan (access), komunikasi (communication), dan mengerti pelanggan (understanding the customer). 


\section{Vol 5 No 1 (2022) 60-70 P-ISSN 2620-295 E-ISSN 2747-0490 DOI: $1047467 /$ elmal.v5i1.633}

\section{Implementasi Syariah}

Implementasi adalah pelaksanaan keputusan, kebijakan dasar yang biasanya berbentuk undang-undang, dapat pula berbentuk perintah dan keputusan badan peradilan. Dapat dikatakan bahwa Implementasi syariah adalah pelaksanaan dan penerapan ajaran islam dalam kegiatan muamalah agar sesuai dengan ajaran dan aturan islam.

\section{Minat}

Dalam Kamus Besar Bahasa Indonesia minat adalah kecenderungan hati yang tinggi terhadap suatu gairah atau keinginan. Minat adalah satu perangkat mental yang terdiri dari perasaan, harapan, pendirian prasangka atau kecenderungan lain yang mengarahkan individu kepada suatu pilihan tertentu.

menurut Mikarsa dalam Wiwin (2021:7) mengatakan minat adalah dorongan dari dalam diri seseorang atau faktor yang menimbulkan ketertarikan dan perhatian secara selektif yang menyebabkan dipilihnya suatu objek yang menguntungkan, menyenangkan dan memberikan kepuasan dalam dirinya, sebaliknya jika kepuasan berkurang maka minat seseorangpun akan berkurang.

Menurut Yudrik Jahja dalam Muhammad Hilmi (2018:15) minat adalah suatu dorongan yang menyebabkan terkaitnya perhatian individu pada objek tertentu seperti pekerjaan, pelajaran, benda, dan orang.

Adapun beberapa faktor yang mempengaaruhi minat menurut Crow dan Crow dalam Rukmanasari (2017:34) yaitu:

a. Dorongan dari dalam, yaitu dorongan dan keinginan dalam diri seseorang, yang menyebabkan-nya ingin tahu terhadap sesuatu yang baru yang menimbulakn minat tertentu.

b. Motif sosial, yaitu motif yang terjadi karena hasrat seseorang yang berhubungan dengan faktor dari diri sendiri sehingga timbul minat. Motif ini membuat seseorang menaruh minat dengan suatu aktifitas agar dapat diakui oleh lingkungan, seperti status sosial.

c. Faktor emosional, yaitu faktor yang berasal dari dalam diri seseorang yang berupa dorongan-dorongan emosional dan pengalaman yang diperoleh seseorang.

Selain faktor-faktor yang mempengaruhi minat, adapula macam-macam minat menurut Abdul dan Muhib dalam Elisna (2018:17) yaitu:

1) Berdasarkan timbulnya, minat dibedakan menjadi minat primitive dan minat kultural. Minat primitive adalah minat yang timbul karena kebutuhan biologis, seperti makan, perasaan nyaman, dll. Sedangkan minat kultural adalah minat yang timbul karena proses belajar seseorang, minat ini tidak secara langsung berhubungan dengan diri kita seperti, keinginan untuk kaya, memiliki barang barang mewah, dll. 
Vol 5 No 1 (2022) 60-70 P-ISSN 2620-295 E-ISSN 2747-0490 DOI: 1047467/elmal.v5i1.633

2) Berdasarkan arahnya, minat dibedakan menjadi minat intrinsik dan minat ekstrinsik. Minat intrinsik adalah minat yang berhubungan dengan aktiftas, yang merupakan minat asli seseorang. Sedangkan minat ekstrinsik adalah minat yang di lakukan karena memiliki tujuan, seperti anak yang rajin belajar kanrna ingin dipuji.

3) Berdasarkan cara mengungkapkannya, minat dibedakan menjadi empat yaitu:

a) Expressed interenst: yaitu minat yang cara mengungkapkannya meminta kepada orang lain untuk menyatakan atau menuliskan kegiatan yang disenangi

b) Manifest interest, adalah minat yang diungkapkan dengan mengobservasi atau melakukan pengamatan secara langsung aktivtas yang dilakukan.

c) Tesed interest, yaitu minat yang diungkapkan dengan cara menyimpulkan hasil tes objektif yang diberikan, nilai yang tinggi pada suatu bahasan biasanya menunjukan minat yang tinggi pula pada hal tersebut.

d) Infonteried interest, yaitu minat yang diungkapkan dengan menggunakan alat yang sudah di standarisasikan, biasanya berisi petanyan yang ditujukan pada subjek terhadap sejumlah aktifitas atau objek.

\section{METODE PENELITIAN}

Pada penelitian kali ini, peneliti akan menggunakan metode penelitian kuantitatif, yaitu kegiatan pengumpulan, pengolahan, analisis, dan penyajian data berdasarkan jumlah secara objektif untuk memecahkan suatu masalah atau menguji suatu hipotesis untuk mengembangkan prinsip-prinsip umum. (Nikolass Duli:2019:3)

Menurut sugiyono (2015:17) metode penelitian kuantitatif adalah metode penelitian yang berdasarkan pada filsafat positivisme yang digunakan untuk meneliti populasi atau sampel tertentu. dengan cara pengambilan sampel secara random, dan pengumpulan data menggunakan instrrumen penelitian, analisis data bersifat kuantitatif atau statistik dengan tujuan untuk menguji hipotesis yang telah ditentukan.

\section{Populasi dan Sampel}

Menurut sugiyono (2011) populasi adalah wilayah generalisasi yang terdiri atas subyek dan obyek yang mempunyai karakteristik tertentu. Dalam penelitian ini karakter yang digunakan oleh penelti yaitu warga Kota Depok yang berusia 20 sampai 40 tahun yang memiliki kemungkinan menggunakan jasa pegadaian syariah. Yang kemudian dipelajari dan ditarik kesimpulan nya. Dalam penelitian ini populasi adalah warga Kota Depok yang berusia 20 sampai dengan 40 tahun. 


\section{Vol 5 No 1 (2022) 60-70 P-ISSN 2620-295 E-ISSN 2747-0490 DOI: $1047467 /$ elmal.v5i1.633}

Menurut Sugiyono (2011) sampel adalah bagian dari jumlah dan karakteristik yang dimiliki oleh populasi. Bila sampel yang diambil memiliki populasi yang besar makan peneliti tidak akan bisa meneliti semua populasi itu karena beberapa kendala seperti dana, dan waktu. Maka dari itu peneliti bisa menggunakan sampel untuk mengambil kesimpulan yang dapat mewakili populasi itu, oleh karena itu sampel yang diambil oleh peneliti harus benar-benar representative (meakili) populasi yang ada.

Dalam penelitian ini, sampel yang digunakan adalah warga kota Depok yang berusia 20 sampai 40 tahun. Menrut Badan Statistik Kota Depok, wwagra yang berusia 20 sampai 40 tahun pada tahun 2019 berjumlah 886.764 orang. Untuk sampel yang akan digunakan dalam penelitian ini dapat dihitung menggunakan rumus Slovin, dan didapatkan sampel sebanyak 100 responden.

\section{HASIL DAN PEMBAHASAN}

\section{Coefficients $^{\mathrm{a}}$}

\begin{tabular}{|l|r|r|r|r|r|}
\hline \multirow{2}{*}{ Model } & \multicolumn{2}{|c|}{$\begin{array}{c}\text { Unstandardized } \\
\text { Coefficients }\end{array}$} & $\begin{array}{c}\text { Standardized } \\
\text { Coefficients }\end{array}$ & \multirow{2}{*}{} & \\
\cline { 2 - 5 } & \multicolumn{1}{|c|}{$\mathrm{B}$} & Std. Error & \multicolumn{1}{|c|}{ Beta } & \multicolumn{1}{c|}{$\mathrm{t}$} & \multicolumn{1}{c|}{ Sig. } \\
\hline 1 (Constant) & -.495 & 1.755 & & -.282 & .779 \\
Promosi & .374 & .071 & .409 & 5.292 & .000 \\
kualitas pelayanan & .287 & .079 & .437 & 3.608 & .000 \\
implementasi & .083 & .128 & .074 & .646 & .520 \\
syariah & & & & & \\
\hline
\end{tabular}

(Sumber: Data primer yang diolah peneliti,2021)

Berdasarkan tabel 4.8 diatas, perhitungan analisis uji t adalah sebagai berikut:

1. Diketahui nilai sig. untuk pengaruh $\mathrm{X} 1$ terhadap $\mathrm{Y}$ sebesar $0,000<0,05$ sehingga dapat disimpulkan bahwa Ho ditolak dan Ha diterima, yang berarti Promosi (X1) bepengaruh signifikan terhadap Minat (Y)

2. Diketahui nilai sig. untuk pengaruh $\mathrm{X} 2$ terhadap $\mathrm{Y}$ sebesar $0,000<0,05$ sehingga dapat disimpulkan bahwa Ho ditolak dan Ha diterima, yang berarti Kualitas Pelayanan (X2) bepengaruh signifikan terhadap Minat (Y)

3. Diketahui nilai sig. untuk pengaruh $\mathrm{X} 3$ terhadap $\mathrm{Y}$ sebesar $0,520>0,05$ sehingga dapat disimpulkan bahwa Ho diterima dan Ha ditolak, yang berarti Implementasi Syariah (X3) tidak bepengaruh signifikan terhadap Minat (Y) 
Vol 5 No 1 (2022) 60-70 P-ISSN 2620-295 E-ISSN 2747-0490 DOI: 1047467/elmal.v5i1.633

\begin{tabular}{|l|r|r|r|r|r|}
\hline ANOVA & \\
\hline Model & \multicolumn{1}{|c|}{$\begin{array}{l}\text { Sum of } \\
\text { Squares }\end{array}$} & Df & Mean Square & F & Sig. \\
\hline Regression & 1986.179 & 3 & 662.060 & 79.461 & $.000^{\mathrm{a}}$ \\
Residual & 799.861 & 96 & 8.332 & & \\
Total & 2786.040 & 99 & & & \\
\hline
\end{tabular}

(Sumber: Data primer yang diolah peneliti,2021)

Berdasarkan tabel 4.9 diatas, hasil analisis uji f, nilai signifikan pengaruh variabel $\mathrm{X} 1, \mathrm{X} 2, \mathrm{X} 3$ secara simultan terhadap variabel $\mathrm{Y}$ adalah sebesar 0,000 , dimana $0,000<$ 0,05. Sehingga dapat disimpulkan bahwa Ho ditolak dan Ha diterima, yaitu variabel Promosi (X1), Kualitas Pelayanan (X2), dan Implementasi Syariah (X3) secara simultan berpengaruh signifikan terhadap Minat (Y).

Berdasarkan data primer atau kuesioner yang telah peneliti olah dengan bantuan spss versi 16 , maka peneliti mendapat pembahasan sebagai berikut.

a. Pengaruh Promosi terhadap Minat masyarakat menggunakan jasa pegadaian syariah

Hasil penelitian menunjukan bahwa promosi berpengaruh secara signifikan terhadap minat masyarakat menggunakan jasa pegadaian syariah. Hasil uji statistik menunjukan nilai signifikansi sebear 0,000 $<0,05$.

Dalam penelitian ini berarti semakin banyak dan bagus promosi yang dilakukan oleh pegadaian syariah maka masyarakat-pun akan semakin tertarik dalam menggunakan jasa pegadaian syariah.

Penelitian ini didukung oleh penelitian Shinta Ardilatul Jannah (2017) yang menyatakan bahwa promosi memiliki pengaruh yang signifikan terhadap promosi dengan signifikansi $0,000<0,05$. Yang artinya jika kegiatan promosi ditingkatkan maka minat masyarakat menggunakan pegadaian syariah pun meninggkat.

Penelitian ini juga tidak sejalan dengan penelitian yang dilalkukan oleh Feti Rukmana sari (2017) yang menyatakan bahwa promosi tidak berpengaruh signifikan terhadap minat menggunakan pegadaian syariah dimana signifikansi 0,884 >0,05.

b. Pengaruh Kualitas Playanan terhadap Minat masyarakat menggunakan jasa pegadaian syariah

Hasil penelitian menunjukan bahwa kualitas pelayanan berpengaruh secara signifikan terhadap minat masyarakat menggunakan jasa pegadaian syariah. Hasil uji statistik menunjukan nilai signifikansi sebear $0,000<0,05$. 
Vol 5 No 1 (2022) 60-70 P-ISSN 2620-295 E-ISSN 2747-0490 DOI: $1047467 /$ elmal.v5i1.633

Dalam penelitian ini berarti semakin baik pelayanan yang dilakukan oleh pegadaian syariah, maka akan meningkatkan minat masyarakat dalam menggunakan jasa pegadaian syariah.

Hasil Penelitian ini didukung oleh penelitian Feti Rukmanasari (2017) yang menyatakan bahwa kualitas pelayanan memiliki pengaruh yang signifikan terhadap minat menggunakan jasa pegadaian syariah dengan signifikansi $0,000<0,05$.

c. Pengaruh Implementasi Syariah terhadap Minat masyarakat menggunakan jasa pegadaian syariah

Hasil penelitian menunjukan bahwa implementasi syariah berpengaruh secara signifikan terhadap minat masyarakat menggunakan jasa pegadaian syariah. Hasil uji statistik menunjukan nilai signifikansi sebear 0,520>0,05.

Menurut wawancara yang peneliti lakukan kepada beberapa responden, mengapa mereka tidak menjadikan implementasi syariah sebagai pilihan dalam menggunakan jasa keuangan khususnya pada pegadaian syariah, dikarenakan ketidak-tahuan responden terhadap perbedaan pegadaian syariah dan konvensional, sehingga responden menganggap sama saja antara pegadaian syariah dan konvensional. perihal riba dan unsur-unsur syariat dalam pegadaian syariah responden menganggapnya sama, hanya dibedakan namanya saja dengan bahasa Arab untuk memberikan perbedaan.

Adapula yang mengetahui perbedaan pegadaian syariah dan konvensional, namun lebih memilih menggunakan jasa pegadaian konvensional karena merasa lebih aman dan memiliki persyaratan yang lebih mudah juga pencairan dana yang lebih cepat. Adapula yang memilih menggunakan pegadaian dan lembaga keuangan konvensional karna khawatir akan penipuan yang berkedok syariah.

Hasil penelitian ini tidak sejalan dengan penelitian Muhammad Hafidz Mauludi, dkk. (2019). Yang menyatakan bahwa implementasi syariah memiliki pengaruh yang signifikan terhadap minat menggunakan pegadaian syariah dengan signifikansi sebesar $0,001<0,05$.

d. Pengaruh Promosi, Kualitas Pelayanan, dan Implementasi Syariah terhadap Minat masyarakat menggunakan jasa pegadaian syariah

Hasil penelitian menunjukan bahwa promosi, kualitas pelayanan, dan implementasi syariah berpengaruh secara signifikan terhadap minat masyarakat menggunakan jasa pegadaian syariah. Hasil uji statistik menunjukan nilai signifikansi sebear $0,000<0,05$. Bagi Indonesia yang merupakan salah satu negara dengan mayoritas muslim terbesar didunia, sangatlah penting untuk menerapkan ekonomi syariah dinegara ini salah satu caranya adalah dengan menggunakan lembaga syariah dalam bebagai transaksi. 


\section{Vol 5 No 1 (2022) 60-70 P-ISSN 2620-295 E-ISSN 2747-0490 DOI: $1047467 /$ elmal.v5i1.633}

\section{KESIMPULAN}

Penelitian ini bertujuan untuk mengetahui apakah terdapat pengaruh antara variabel promosi, kualitas pelayanan, dan implementasi syariah terhadap minat masyarakat menggunakan jasa pegadaian syariah. Berdasarkan hasil penelitian dan pembahasan dalam bab IV, maka dapat diambil kesimpulan:

1. Dalam penelitian ini variabel promosi memiliki pengaruh secara signifikan terhadap minat masyarakat menggunakan jasa pegadaian syariah. Hal ini dibuktikan oleh nilai signifikansi sebesar 0,000. Dimana $0,000<0,05$ yang berarti Ho ditolak dan Ha diterima.

2. Dalam penelitian ini variabel kualitas pelayanan memiliki pengaruh secara signifikan terhadap minat masyarakat menggunakan jasa pegadaian syariah. Hal ini dibuktikan oleh nilai signifikansi sebesar 0,000. Dimana 0,000 $<0,05$ yang berarti Ho ditolak dan Ha diterima.

3. Dalam penelitian ini variabel implementasi syariah memiliki pengaruh secara signifikan terhadap minat masyarakat menggunakan jasa pegadaian syariah. Hal ini dibuktikan oleh nilai signifikansi sebesar 0,520. Dimana $0,520>0,05$ yang berarti Ho diterima dan Ha ditolak.

4. Dalam penelitian ini variabel promosi, kualitas pelayanan, dan implementasi syariah secara simultan memiliki pengaruh secara signifikan terhadap minat masyarakat menggunakan jasa pegadaian syariah. Hal ini dibuktikan oleh nilai signifikansi sebesar 0,000. Dimana $0,000<0,05$ yang berarti Ho ditolak dan Ha diterima.

\section{DAFTAR PUSTAKA}

Huzein, M. H. (2018). Pengaruh kualitas produk terhadap minat nasabah menggunakan jasa PT. Pegadaian (Persero) Unit Pegadaian Syariah Sadabuan (Doctoral dissertation, IAIN Padangsidimpuan).

Mu'ah dan masram. (2021). Loyalitas pelanggan tinjauan aspek kualitas pelayanan dan biaya peralihan. Sidoarjo: Zifatama Publisher.

Nasution, E. S. (2018). Pengaruh faktor sosial, pribadi, promosi terhadap minat masyarakat Lingkungan 3 Pasar Sibuhuan untuk menggunakan jasa pegadaian syariah (Doctoral dissertation, IAIN Padangsidimpuan). 


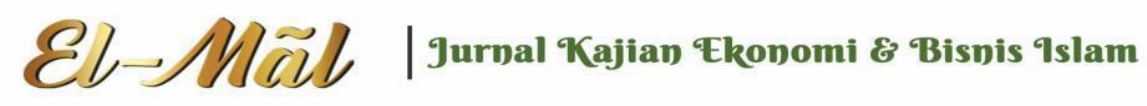

\section{Vol 5 No 1 (2022) 60-70 P-ISSN 2620-295 E-ISSN 2747-0490} DOI: $1047467 /$ elmal.v5i1.633

Rangkuti, Freddy. (2009). strategi komunikasi yang kreatif dan analisis kasus integrated marketing communication. Bogor: PT.mardiyuana.

Rukmanasari, F. (2017). Pengaruh Pengetahuan, Promosi dan Kualitas Pelayanan Terhadap Minat Nasabah Menggunakan Jasa Pegadaian Syariah (Studi Kasus Pada Pegadaian Syariah Majapahit Semarang) (Doctoral dissertation, IAIN).

Warnadi dan Triyono, Aris. (2019). Manajemen Pemasaran. Yogyakarta: CV.Budi Utama. 